\title{
Influence of Size and Construction Schedule of Massive Concrete Structures on Its Temperature Regime
}

\author{
Nikolay Aniskin ${ }^{1}$, Chuc Nguyen Trong ${ }^{1, *}$ and Long Hoang Quoc ${ }^{2}$ \\ ${ }^{1}$ Moscow State University of Civil Engineering, Yaroslavskoe shosse, 26, Moscow, 129337, Russia \\ ${ }^{2}$ Le Quy Don Technical University, Ha Noi, Vietnam
}

\begin{abstract}
Cracking is an important problem in the process of building a concrete massive structure. The overwhelming majority of cracks occurring in the concrete are usually caused by temperature effects. Because of this, it is essential to control and regulate temperature, it is necessary to prevent cracking. The formation of the temperature regime of a massive structure is affected by a large number of factors: its size; cement consumption and its maximum heat release; temperature of the concrete to be laid; ambient temperature, etc. In this paper, we consider the influence of the size and construction schedule of a massive concrete structure on its temperature regime. Using the computer program Midas civil 2011, the temperature regime was calculated, maximum temperatures were obtained in massive concrete and massive concrete columns with different sizes. The analysis of possible fracture for different values of the factors are considered.
\end{abstract}

\section{Introduction}

According to the definition given by the American Committee Institute on Concrete "massive concrete element" can be called a concrete structural element wherein the concrete curing is accompanied by considerable heat generation and large unevenness of the temperature field due to exothermic cement. As a result of this, due to the possibility of crack formation, it is necessary to use measures to prevent it [1]. Massive concrete structures most often encountered in practice, the energy and hydraulic engineering, foundation engineering, the construction of bridges, etc. [2]. According to the recommendations of the Committee for the "massive concrete structures" include structures with dimensions are more than 3 feets or 1 meter in different directions [3].

One of the main problems encountered in the construction of concrete arrays is the problem of the temperature cracking resistance of concrete masonry during construction process. Due to the heat of hydration of cement in the mass concrete structure during construction, there is a great temperature difference between the concrete core and the array surface. As a result, the formation of cracks on the concrete surface caused by thermal stress at an early age of concrete is the result of this mechanism [4-6].

*Corresponding author: ntchuc.mta198@gmail.com 
The formation of the temperature regime of a concrete massive is affected by a large number of factors: intensity of concreting; the size of the concrete massive; consumption of cement; the temperature of the concrete to be laid; maximum heat release; the season of laying concrete massive etc. [7-8].

In this paper, the influence of the size of a single massive concrete block and the speed of column concrete pouring on their temperature regime is considered.

\section{Methods}

Numerical modeling of the temperature non-stationary problem with allowance for heat release during hydration of cement is based on the solution of the known equation of the theory of heat conduction [9-10].

$$
k \nabla^{2} T+Q=\rho c \frac{\partial T}{\partial \tau}
$$

where: $\mathrm{T}$ - temperature function, ${ }^{0} \mathrm{C}$;

$\mathrm{k}$ - is the thermal conductivity of the material, $\mathrm{m}^{2} / \mathrm{s}$;

$\mathrm{c}$ - is the specific heat of the material, $\mathrm{kJ} / \mathrm{kg}$;

$\rho$ - the density of the material, $\mathrm{kg} / \mathrm{m}^{3}$;

$\mathrm{Q}$ - is the heat released during hydration, $\mathrm{kJ} / \mathrm{m}^{3}$;

$\tau$ is the time, day.

When solving equation (1), it is also necessary to use the corresponding boundary conditions.

The most popular of the numerical methods today is the solution of the differential equation (1) - method of finite elements (FEM). All problems in this work were solved by the finite element method using the Midas civil 2011 software [11-12].

\section{Results and discussion}

\subsection{Object of research}

In this paper, we examined the effect of the size of a single massive concrete on its temperature regime. Cubical blocks were examined with dimensions $2 \times 2 \times 2 \mathrm{~m} ; 3 \times 3 \times 3$ $\mathrm{m} ; 4 \times 4 \times 4 \mathrm{~m}$ and $5 \times 5 \times 5 \mathrm{~m}$. Because the investigated array is symmetrical, so can reduce the number of calculations in this paper by using $1 / 4$ part of the design is calculated. The scheme of the design and its calculation model for FEM is shown in Fig. 1.
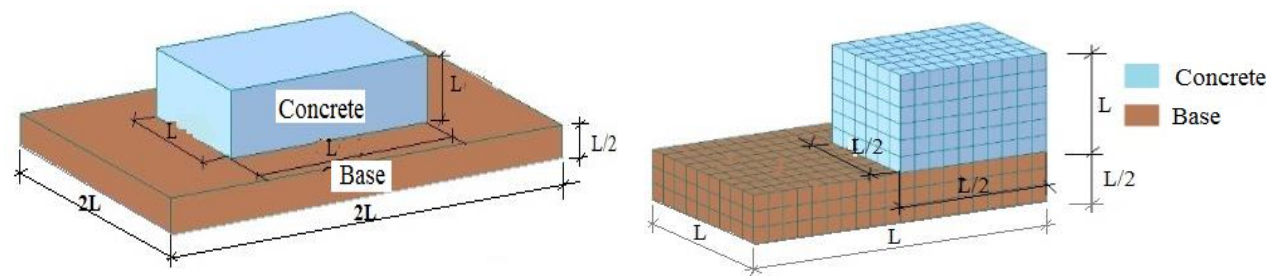

Fig. 1. Calculated block diagram and mesh FEM

Considered the instant construction of the block under the following conditions: ambient temperature $25^{\circ} \mathrm{C}$ (summer period), the initial temperature of the stacked concrete mixture $25^{\circ} \mathrm{C}$ 
(without cooling), and there is lack of special measures for temperature regulation. The characteristics of concrete and soil adopted in the calculations are presented in Table 1. With the help of Midas civil 2011 computer program, the temperature regime was calculated, maximum temperatures in concrete blocks for the four cases considered were obtained.

Table 1. Calculated physical characteristics of materials

\begin{tabular}{|c|l|c|c|}
\hline \multirow{2}{*}{ No } & \multicolumn{1}{|c|}{ Characteristics, units of measure } & \multicolumn{2}{|c|}{ Values } \\
\cline { 3 - 4 } & & concrete & base \\
\hline 1 & Coefficient of thermal conductivity, $\mathrm{W} /\left(\mathrm{m} .{ }^{0} \mathrm{C}\right)$ & 2.6 & 2.0 \\
\hline 2 & Specific heat, $\mathrm{kJ} /\left(\mathrm{kg} .{ }^{0} \mathrm{C}\right)$ & 0.95 & 0.84 \\
\hline 3 & Density of the material, $\mathrm{kg} / \mathrm{m}^{3}$ & 2400 & 2650 \\
\hline 4 & Coefficient of convective heat transfer, $\mathrm{W} /\left(\mathrm{m}^{2}{ }^{\circ} \mathrm{C}\right)$ & 13.94 & 14.00 \\
\hline 5 & Modulus of elasticity, $\mathrm{N} / \mathrm{m}^{2}$ & $2.7 .10^{10}$ & $1.8 .10^{10}$ \\
\hline 6 & The coefficient of linear expansion & $1.10^{-6}$ & $1.10^{-5}$ \\
\hline 7 & Poisson's ratio & 0.18 & 0.2 \\
\hline 8 & The quantity of cement, $\mathrm{kg} / \mathrm{m}^{3}$ & 450 & - \\
\hline 9 & Maximum heat release during hydration of cement, $\mathrm{kJ} / \mathrm{kg}$ & 320 & - \\
\hline
\end{tabular}

Fig. 2. FEM mesh

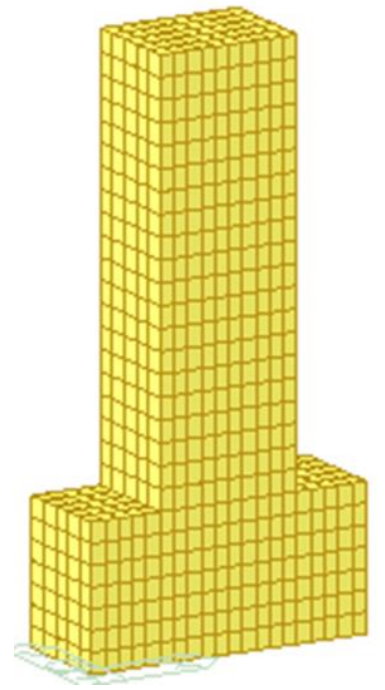

Another factor that significantly influences on the temperature regime of the vertical massive concrete structure is the intensity of concreting. Choosing the value of this factor is very important, because it not only affects to the temperature regime of the massive concrete but also determines the construction time and cost. Such design is widely used in the practice of hydraulic engineering and electrical engineering. The following initial data were taken: the size of the array (height, width, thickness) - 30x10x15 m, the thickness of the laid concrete layers $1.5 \mathrm{~m}$, the maximum heat release of cement $-250 \mathrm{~kJ} / \mathrm{kg}$, cement consumption $-165 \mathrm{~kg} / \mathrm{m}^{3}$, the initial temperature of the concrete mixture $-\mathrm{t}=25^{\circ} \mathrm{C}$. The FEM mesh, which includes 1700 elements and 2328 nodes is shown in Fig.2. Three variants of the intensity of the block construction were considered: $0.2,0.4$ and $0.6 \mathrm{~m} /$ day (elevation speed).

The values of the maximum temperatures obtained inside the massive concrete block for each variant were compared with the permissible values based on the requirements for crack formation. On the basis of these results, the author has been selected the recommended intensity of concrete, ensuring the absence of cracking. 


\subsection{Analysis result}

\subsubsection{The temperature regime of single massive blocks}

The calculated temperature regime results of concrete blocks are shown in Figs. 3 - 4. As can be seen from the obtained results, the block dimensions greatly influence on the value of the maximum temperature in the center of the block and the time of its process.

a

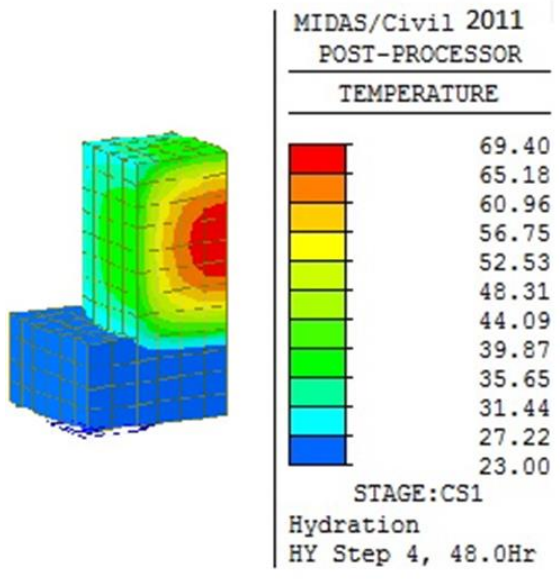

$\mathrm{b}$

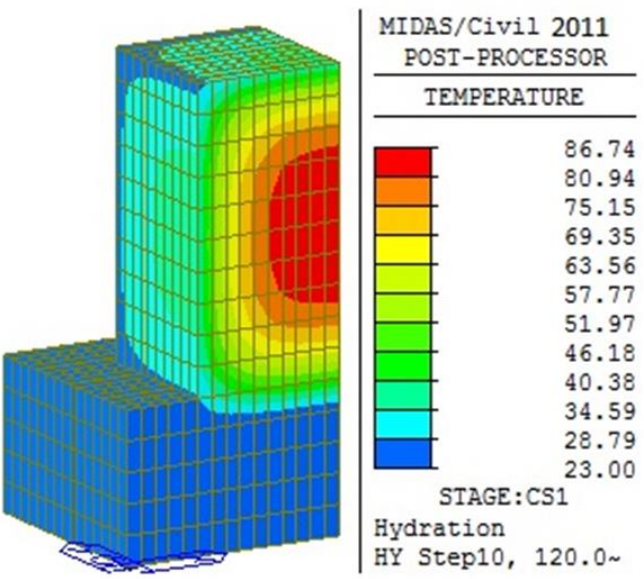

Fig. 3. Temperature distribution in concrete blocks : a - with dimensions $2 \times 2 \times 2 \mathrm{~m}$ at the time 48 hours after laying; $\mathrm{b}$ - with dimensions $5 \times 5 \times 5 \mathrm{~m}$ at the point of time 120 hours after laying

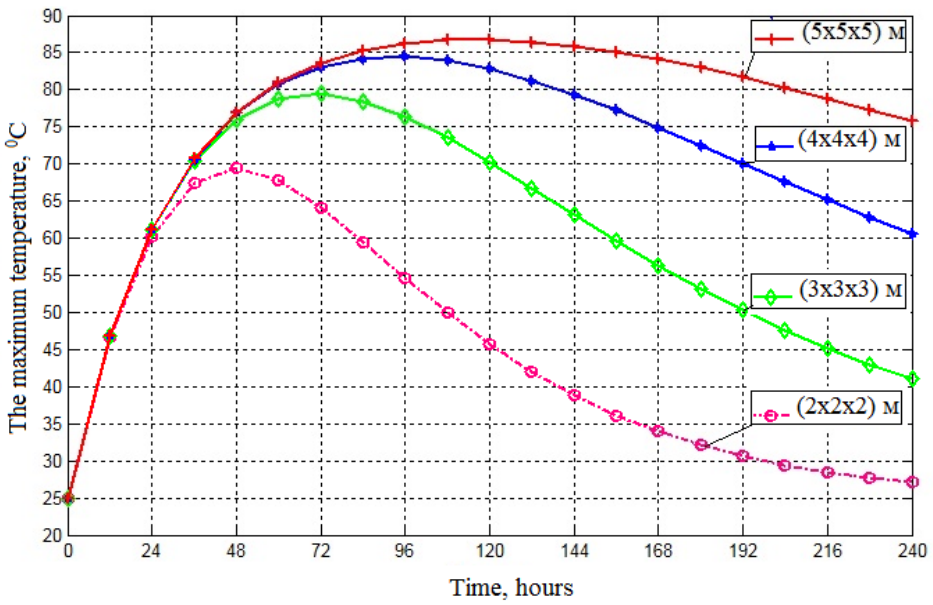

Fig. 4. Temperature distribution in concrete blocks

In Fig. 3 shows graphs of temperature changes in the center of concrete blocks. The magnitude of the maximum temperature of the block size $2 \times 2 \times 2 \mathrm{~m}$ reaches the value of $69.4^{0} \mathrm{C}$ after 48 hours placed the concrete, while the block size $5 \times 5 \times 5 \mathrm{~m}$ reaches the maximum temperature at $86.74^{\circ} \mathrm{C}$. It is also possible to note a sufficiently rapid cooling of $2 \times 2$ $\times 2 \mathrm{~m}$ block internal temperature soon drop to $27.0^{\circ} \mathrm{C}$ after 240 hours be laid, whereas for $5 \times 5$ $\times 5 \mathrm{~m}$ block it only decreases to $75.0^{\circ} \mathrm{C}$.

The maximum temperature differences between the center of block and its surface increased by $30.02^{0} \mathrm{C}$ for $2 \times 2 \times 2 \mathrm{~m}$ block, and up to $51.04^{0} \mathrm{C}$ for $5 \times 5 \times 5 \mathrm{~m}$ block. 
Table 2. Temperature regime of the concrete block

\begin{tabular}{|c|c|c|c|c|}
\hline \multirow{2}{*}{ Parameters } & \multicolumn{4}{|c|}{ Block Size (m) } \\
\hline & $2 \times 2 \times 2$ & $3 \times 3 \times 3$ & $4 \times 4 \times 4$ & $5 \times 5 \times 5$ \\
\hline The maximum temperature, ${ }^{0} \mathrm{C}$ & 69.40 & 78.48 & 84.43 & 86.74 \\
\hline Time of occurrence of the maximum temperature, $\mathrm{h}$ & 48 & 84 & 96 & 120 \\
\hline $\begin{array}{l}\text { The temperature difference between the center of the } \\
\text { block and its surface is } \Delta \mathrm{T},{ }^{0} \mathrm{C}\end{array}$ & 30.02 & 41.12 & 47.22 & 51.04 \\
\hline $\begin{array}{l}\text { The ratio of the surface area to the volume of the } \\
\text { block A/V }\end{array}$ & 3.0 & 2.0 & 1.5 & 1.2 \\
\hline
\end{tabular}

It is known [13], one of the appropriate criteria for cracking temperature occur is the condition for the temperature difference between the center of the block and its surface: $\Delta \mathrm{T}$ $>20^{\circ} \mathrm{C}$. The obtained results showed that in all considered cases this value exceeded $20^{\circ} \mathrm{C}$, which indicates a possible cracking.

As a parameter for determining the relationship between the maximum temperature at the center of the block and its geometric dimensions, the ratio of the area of the block surface to its volume (A/V value in Table 2) was considered.

The effect of this parameter on the maximum temperatures and temperature gradients of concrete blocks is shown in Figs. 5 - 6.

It is obvious that with an increase in the ratio of the surface area to the volume of the block, the temperature, and the temperature drop decrease. These relationships can be expressed by the following linear relations (where $\mathrm{x}$ is $\mathrm{A} / \mathrm{V}$ ):

for maximum temperature - $\mathbf{T}_{\max }=\mathbf{- 9 . 8} \mathbf{x}+\mathbf{9 9}$ (with precision $\mathrm{R}^{2}=99.23 \%$ );

for a temperature drop - $\Delta \mathbf{T}=\mathbf{- 1 2 x}+\mathbf{6 5}$ (with precision $\mathrm{R}^{2}=99.52 \%$ ).

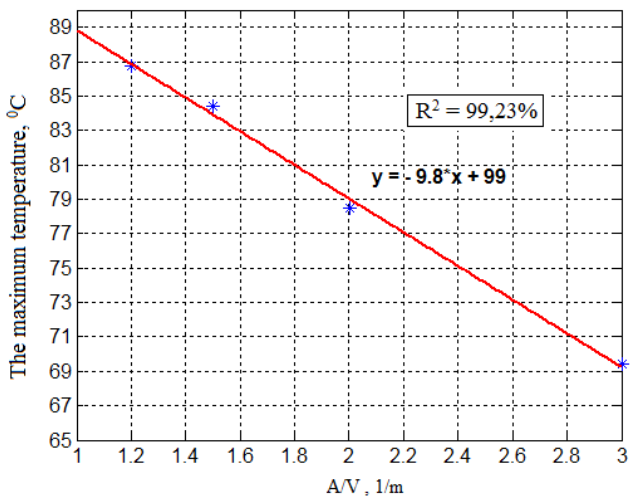

Fig. 5. Effect of $A / V$ on the maximum temperature of concrete blocks

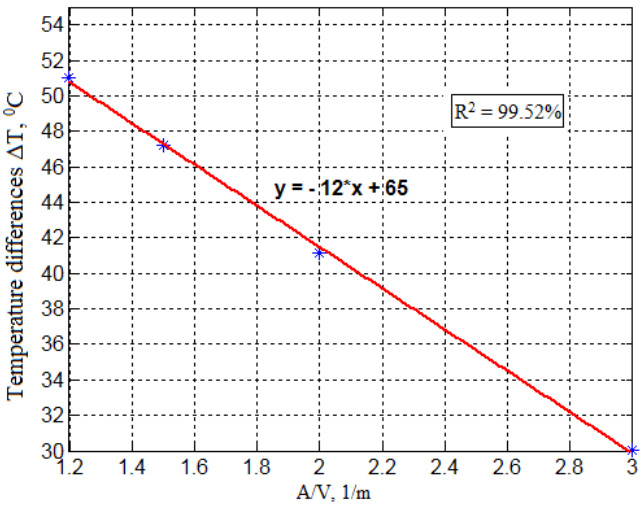

Fig. 6. Effect of $\mathrm{A} / \mathrm{V}$ on the maximum temperature drop of concrete blocks 
Such an approach can be used for preliminary assessment of the temperature regime under appropriate conditions.

\subsubsection{The temperature regime of columnar concrete massifs}

The results obtained from the calculations for the considered variants of the intensity of construction is shown in Fig. 7. As you can see, with the increase in the rate of construction, the temperature inside the array increases.

$$
\begin{aligned}
& \mathrm{V}=0.20 \mathrm{~m} / \text { day } \\
& \mathrm{T}_{\max }=32.61^{\circ} \mathrm{C}
\end{aligned}
$$

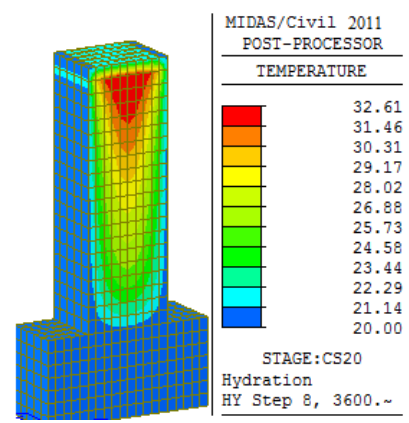

a)

$$
\begin{aligned}
& \mathrm{V}=0.40 \mathrm{~m} / \text { day } \\
& \mathrm{T}_{\max }=35.50^{\circ} \mathrm{C}
\end{aligned}
$$

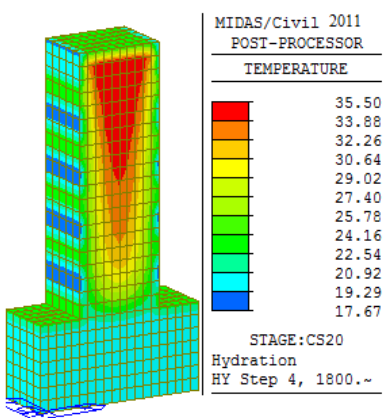

b)

$$
\begin{aligned}
& \mathrm{V}=0.60 \mathrm{~m} / \text { day } \\
& \mathrm{T}_{\max }=41.35^{\circ} \mathrm{C}
\end{aligned}
$$

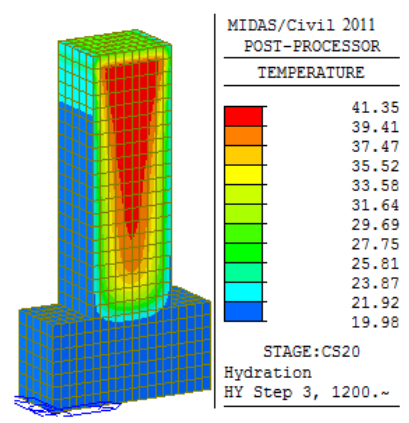

c)

Fig. 7. Temperature distribution in the concrete blocks: a - case 1, b - case 2 and c - case 3

To estimate the possibility of crack formation, we use the technique proposed in [14]. For blocks near the base, the maximum permissible temperature is approximately determined by the formula:

$$
\left[\mathrm{T}_{\sigma}^{\max }\right]=\mathrm{T}_{\sigma}^{\mathrm{cp}} \text { экспл }+\left[\Delta \mathrm{T}_{\sigma}^{\max }\right],
$$

where : $\mathrm{T}_{\sigma}^{\mathrm{cp}}$ экпл - average temperature in the concrete massive for the period of operation;

$\left[\Delta \mathrm{T}_{\sigma}^{\max }\right]$ - the allowable temperature difference in the block for the construction period, defined as:

$$
\left[\Delta \mathrm{T}_{\sigma}^{\max }\right]=\left[\Delta \mathrm{T}_{\tilde{\sigma}}^{\mathrm{cp}}\right] \mathrm{K}_{\text {перех }},\left[\Delta \mathrm{T}_{\sigma}^{\mathrm{cp}}\right]=\frac{\varepsilon_{\mathrm{np}}}{\alpha \mathrm{k}_{3} \mathrm{k}_{\mathrm{p}} \mathrm{k}_{\text {тр }}},
$$

where: is the transition coefficient from the mean temperature in the block during the period of exothermy to the maximum $\left(\kappa_{\text {перех }}=1.3-1.5\right) ; \varepsilon_{\text {nр }}$ - ultimate tensile concrete; $\alpha$ coefficient of linear expansion; $\mathrm{k}_{3}$ - catch factor (average); $\mathrm{k}_{\mathrm{p}}$ - relaxation coefficient (average); $\mathrm{k}_{\text {тр }}$ - safety factor in cracking.

Ultimate extensibility of concrete depend on concrete grade, composition, uniformity, age, for M250 accept $\varepsilon_{\mathrm{np}}=0.8 \cdot 10^{-4}$; coefficient of linear expansion $\alpha=1.10^{-5}$; the relaxation coeffcient $\mathrm{k}_{3} \in \varphi\left(\mathrm{H}_{\text {бл }} / 1_{\text {бл }} ; \mathrm{E}_{\text {бет }} / \mathrm{E}_{\text {осн }}\right)$. In the analysis, values of $\mathrm{H} / 1=0.15$; Ебл/Ебл $=1.39$ are taken. And, the value $\mathrm{k}_{3}=0.70$ was also indicated in graph 15.6 [15]. The relaxation coeffcient $\mathrm{kp}_{\mathrm{p}}=f\left(\tau_{\mathrm{o}}, \tau_{\mathrm{k}}, \Delta \tau\right)$ can be adopted from graph 15.5 [15], and is equal to 0.80 .

Then the values of the quantities from formulas (3) will be equal to: 


$$
\left[\Delta \mathrm{T}_{\sigma}^{\mathrm{cp}}\right]=\frac{0.8 \times 100000}{1.10000 \times 0.7 \times 0.8}=14.29^{\circ} \mathrm{C} ;\left[\Delta \mathrm{T}_{\sigma}^{\max }\right]=14.29 \times 1.3=18.57^{\circ} \mathrm{C}
$$

In addition, the average temperature in the unit during operation $\mathrm{T}_{б}^{\text {ср экспл }} \approx \mathrm{T}_{\text {воздух }}^{\text {ср }}=20^{\circ} \mathrm{C}$.

So, the maximum allowable temperature in concrete block:

$$
\left[\mathrm{T}^{\mathrm{max}}\right]=20+18.57=38.57^{\circ} \mathrm{C} .
$$

Thus, for the maximum intensity of the erection of case 1 and case 2 , the maximum temperature in the depth of the massif was $32.61^{\circ} \mathrm{C}$ and $35.50^{\circ} \mathrm{C}$, respectively, which is less than the maximum permissible temperature of $38.57^{\circ} \mathrm{C}$. Consequently, at these intensities, cracks formation is unlikely. For case 3 , the maximum temperature in the block was $41.35^{\circ}$ $\mathrm{C}$, which exceeds the maximum permissible temperature. Thus, for a given intensity of concrete, there is a high probability of occurrence of temperature cracks.

\section{Conclusion}

Based on the results of the studies, the following conclusions:

1. Temperature regime of massive concrete structure during its construction is largely dependent on its size. With an increase in the ratio of the surface area of the concrete block to its volume, a corresponding decrease in the maximum temperature and temperature difference between the center and the surface of the block occurs.

2. Mathematical dependencies are obtained, which allow predicting temperature parameters according to the geometric characteristics of the block. For rapid evaluation of the temperature regime, it is possible to compile such dependencies for any conditions of construction.

3. The results of the analysis showed that in all considered cases of the erection of individual blocks under given conditions, the temperature difference between the center of the block and its surface exceeded $20^{\circ} \mathrm{C}$. This indicates a possible development of temperature cracks. To reduce the likelihood of crack formation, it is necessary to take appropriate measures.

4. The maximum value of the temperature in the vertical concrete block depends on the intensity of concreting, which determines not only the economic aspects of construction but also affects to the quality of the structure.

5. For the considered intensity of erection under the accepted conditions, the permissible intensity of erecting a columnar block should not exceed $0.4 \mathrm{~m} /$ day. This will reduce the risk of the formation of temperature cracks.

\section{References}

1. ACI Committee 207 - Mass and thermally controlled concrete (2017)

2. Korea Concrete Institute, Thermal crack control of mass concrete (Manual, 2010)

3. K. Barbara, B. Maciej, P. Maciej, Z. Aneta, Proc. Eng., 193 (2017)

4. N. Aniskin, N.T. Chuc, Mat. Web of Confer., 196, 04059 (2018) https://doi.org/10.1051/matecconf/201819604059

5. F. Li, Y. Shen, Eur. J. of Envir. and Civ. Eng., 29 (2015)

6. N.A. Aniskin, Hydr. Eng. Constr., 12 (2005) 
7. N.A. Aniskin, N.T. Chuc, IOP Conf. Series: Mater. Sci. and Eng., 365 (2018) Doi:10.1088/1757-899X/365/4/042083

8. M.H. Lee, B.S. Khil, H.D. Yun, Indi. J. of Eng. \& Mater. Sci., 8 (2014)

9. P. Havlásek, V. Šmilauer, K. Hájková, and L. Baquerizo, Mater. Sci. and Eng. 236 (2017)

10. A. Rahimi, J. Noorzaei, Aus. J. of Bas. and Appl. Sci., 12 (2011)

11. J.E Akin, Finite Element for Analysis and Design (Academic Press, 1994)

12. MIDAS Information Technology, Heat of Hydration - Analysis Analysis Manual, Version - (2011)

13. Zhu Bofang, Thermal stresses and temperature control of mass concrete, (the United States of America 2014)

14. N.A. Aniskin, N. Hoang, Ves. MGSU, 8 (2014)

15. V. I. Teleshev, Fundamentals and methods of design and construction of concrete dams in particularly harsh climatic conditions (St. Petersburg, 2003) 